\title{
ABOUT SOME TRANSCENDENTAL NUMBERS
}

\section{Jamel Ghanouchi}

\section{RIME department of Mathematics}

Abstract. Mathematicians of the XIX century have proved that $\pi$, e and the Champernowne number are transcendentals, but what about $\pi+e$ or $\pi e$ ? The Riemann hypothesis can it be generalized? In this paper, we demonstrate a method in order to know if it is possible to solve these two problems.

\section{The approach of the first problem}

A number is transcendental if it is not the root of a polynomial equation : $a_{n} x^{n}+a_{n-1} x^{n-1}+\ldots+a_{0}=0$ where the coefficients are rationals and different 0 it would be algebraic. We know since the XIX century that $\pi$, a and the Ch mpenown umb cr are transcendentals but we do not know anything about their sum, eir o ferenc of their product.Effectively if $\mathrm{A}$ is algebraic and $\mathrm{B}$ is transcendental, $\mathrm{A}+\mathrm{B}$ an $\mathrm{A}$ ransce dentals, but if $\mathrm{A}$ is also transcendental we still do not the nature of $\mathrm{AB}, \mathrm{A}-\mathrm{B}, \mathrm{A}+\mathrm{B}$. $\mathrm{H}$, tri to solve this problem.

\section{Definition}

A real number is composound if it can be written as

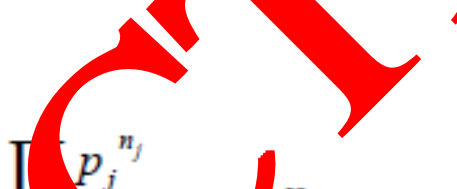
are rationals. This decomposition in prime fa ${ }^{\circ}$ is uniqu prime real number can be written only as $\mathrm{p}=\mathrm{p} .1$. Thus we define other $r$ eal prin nubers like $\pi, \mathrm{e}, \ln (2)$. Thus $\sqrt[q]{p}=p^{\frac{1}{q}}$ is compound. Also $\sqrt[q]{p}+1=p^{\frac{1}{q}}$ $\sqrt[2]{p}-1=(p-1)(\sqrt[2]{p}+1)^{-2}\left(\sqrt[2]{p}+1 \cdot\left(\sqrt{p+1)^{-1}}\right.\right.$ compound, for example.

\section{Theorem}

If $\mathrm{T}$ and $\mathrm{T}$ ' are 'sscen talprime numbers then $\mathrm{T}+\mathrm{T}$ ', $\mathrm{T}-\mathrm{T}$ ' and $\mathrm{TT}$ ' are transcendentals.

\section{Proof of}

Let $C$ C'

1) $C C^{\text {th }}$, me and algebraics.

2) $C C^{\prime n}$ is a braic and $C+m C^{\prime}$ is transcendental.

3) $C C^{\prime n}$ is tran ,cendental and $C+m C^{\prime}$ is algebraic.

4) $C C^{\prime n}, C+m C^{\prime}$ are transcendentals.

\section{Thus}

1) $C C^{n}+m C^{n+1}=\left(C+m C^{\prime}\right) C^{n}=A+m C^{n+1}=A^{\prime} C^{\prime n}$ where $\mathrm{A}$ and $\mathrm{A}^{\prime}$ are algebraics and $\mathrm{C}^{\prime}$ is solution of an algebraic equation, it is impossible !

2) $C C^{\prime n}, C C^{\prime n^{\prime}}$ are algebraics and $C C^{\prime n}\left(C C^{\prime n}\right)-1 C^{\prime n-n^{\prime}}$ is algebraic if $\mathrm{n}=\mathrm{n}$ '. There is only one $\mathrm{n}=\mathrm{M}$ for which $C C^{\prime n}$ is algebraic, all the others are transcendentals. If $\mathrm{M}$ is not unique, there are three possibilities : $C C^{\prime \prime}\left(C^{\prime \prime} C^{\prime \prime \prime}\right)^{n}$ is transcendental for all $\mathrm{n}$ or $C C^{\prime \prime-1}\left(C^{\prime} C^{\prime \prime \prime-1}\right)^{n}$ is transcendental for all $\mathrm{n}$ or there exists $\mathrm{L}, \mathrm{L}$ ' for which

$C C^{\prime M}=A, C^{\prime \prime} C^{\prime \prime \prime} M^{\prime}=A^{\prime}, C C^{\prime \prime}\left(C^{\prime} C^{\prime \prime \prime}\right)^{L}=A^{\prime \prime}, C C^{\prime \prime-1}\left(C^{\prime} C^{\prime \prime \prime}-1\right)^{L_{1}}=A^{\prime \prime \prime}$ are algebraics. 


$$
\begin{aligned}
& A^{2} C^{\prime L+L^{\prime}-2 M} C^{m{ }^{\prime \prime} L-L^{\prime}} \quad A^{\prime \prime} A^{\prime \prime \prime} \\
& A^{\prime 2} C^{\prime L-L^{\prime}} C^{m{ }^{m} L+L^{\prime}-2 M^{\prime}} \quad A^{\prime \prime} A^{m m^{\prime \prime 1}} \\
& C^{\prime X} \quad B C^{m{ }^{m} Y} \\
& C^{1-Y} \quad D C^{1{ }^{m Z}} \\
& X=L^{\prime}+L-2 M \\
& Y=L^{\prime}-L \\
& Z=-\left(L+L^{\prime}-2 M^{\prime}\right) \\
& B \quad A^{\prime \prime} A^{\prime \prime} A^{-2} \\
& D A^{\prime 2} A^{\prime \prime-1} A^{\prime \prime \prime}
\end{aligned}
$$

And

$A A^{\prime} C^{, L-M} C^{m{ }^{m-M}} A^{\prime \prime}$

$A A^{1-1} C^{L^{\prime}-M} C^{m M^{1} M^{\prime}-L^{\prime}} \quad A^{\prime \prime \prime}$

$C^{, U} \quad E C^{m !}$

$C^{, U^{\prime}} \quad F C^{m V^{\prime}}$

$U=L^{\prime}-M$

$V=M^{\prime}-L$

$U^{\prime}=L^{\prime}-M$

$V^{\prime}=L^{\prime}-M^{\prime}$

E $A^{\prime \prime} A^{-1} A^{-1}$

F $A^{\prime \prime \prime} A^{-1} A^{\prime}$

$C^{1^{-X Y}}=B^{-Y} C^{m^{-Y^{2}}}=D^{X} C^{m,{ }^{\prime \prime}} \Rightarrow\left(L-L^{\prime}=X Z=-\left(L+L^{\prime}-2 M\right)\left(L+L^{\prime}-2 M^{\prime}\right)\right.$

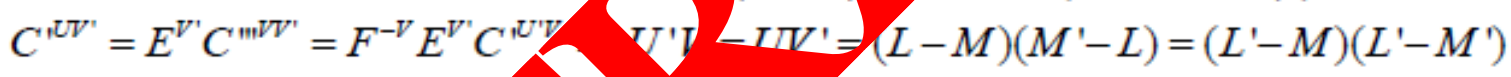

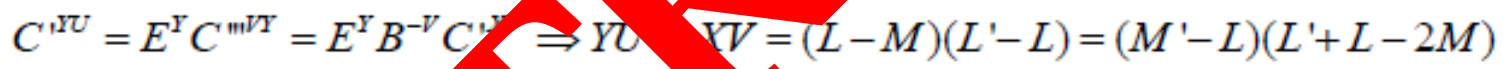

$C^{\prime Z U}=E^{z} C^{\prime \prime \prime Z V}=E^{z} D\left(\quad \Rightarrow Z U \triangleq V Y=-\left(L+L^{\prime}-2 M^{\prime}\right)\left(L^{\prime}-M\right)=-\left(L^{\prime}-L\right)\left(L^{\prime}-M^{\prime}\right)\right.$

$\Rightarrow L^{2}+L^{\prime 2}-2 L L^{\prime}=L^{\prime 2}+-2\left(M^{\prime}+M\right)\left(L+L^{\prime}\right)+4 M M^{\prime}$

$\Rightarrow M^{2}+M^{\prime 2}-M^{\prime} M^{\prime} Y^{2}+M^{\prime}+2 M M^{\prime}-2\left(M^{\prime}+M\right)\left(L+L^{\prime}\right)+4 L L^{\prime}$

$\left.\Rightarrow\left(M-M^{\prime}\right)^{-}=-M^{\prime}-L\right)\left(M+M^{\prime}-2 L^{\prime}\right)$

Thus

$\left(L-\gamma\left(L^{\prime}-M^{\prime}\right)=\left(L^{\prime}-L\right)\left(L^{\prime}+L-2 M\right)+\left(M-L^{\prime}\right)\left(L^{\prime}-M^{\prime}\right)\right.$

$\left(L^{\prime}-M,\left(M^{\prime}-L\right)\left(L^{\prime}-M\right)+\left(M^{\prime}-L\right)(L-M)\right.$

$\left(L^{\prime}-M\right)\left(L \vee y-M^{\prime}\right)=\left(M^{\prime}-L\right)(L-M)=\left(L^{\prime}-M\right)\left(L^{\prime}-M^{\prime}\right)$

$\Rightarrow\left(L^{\prime}-M\right)(\mathcal{L}-M)=0 \Rightarrow\left(M^{\prime}-L\right)\left(M^{\prime}-L^{\prime}\right)=0$

We deduce

$\mathrm{M}=\mathrm{M}^{\prime}=\mathrm{L}=\mathrm{L}^{\prime}$ is unique !

3) $C+m C^{\prime}-\left(C+m^{\prime} C^{\prime}\right)=\left(m-m^{\prime}\right) C^{\prime} \Rightarrow m=m^{\prime}$ because this number is algebraic at this condition. There is only one $\mathrm{m}=\mathrm{N}$ for which $\mathrm{C}+\mathrm{mC}^{\prime}$ is algebraic, all the others are transcendentals. If $\mathrm{N}$ is not unique there are three possibilities :

$\mathrm{C}+\mathrm{C}$ " $+\mathrm{m}(\mathrm{C}+\mathrm{C}$ "' $)$ is transcendental for all $\mathrm{m}, \mathrm{C}-\mathrm{C}$ " $+\mathrm{m}(\mathrm{C}$ '-C"') is transcendental for all $\mathrm{m}$ or

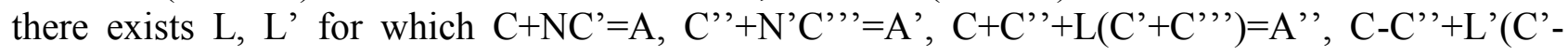
$\mathrm{C}^{\prime \prime}$ ') $=\mathrm{A}$ "' are algebraics, thus

$\mathrm{A}^{\prime \prime}+\mathrm{A}^{\prime \prime \prime}=2 \mathrm{~A}+\left(\mathrm{L}+\mathrm{L}^{\prime}-2 \mathrm{~N}\right) \mathrm{C}^{\prime}+\left(\mathrm{L}-\mathrm{L}^{\prime}\right) \mathrm{C}^{\prime \prime}$, 
$\mathrm{A}^{\prime \prime}-\mathrm{A}^{\prime \prime \prime}=2 \mathrm{~A}^{\prime}+\left(\mathrm{L}-\mathrm{L}^{\prime}\right) \mathrm{C}^{\prime}+\left(\mathrm{L}+\mathrm{L}^{\prime}-2 \mathrm{~N}^{\prime}\right) \mathrm{C}^{\prime \prime}$,

$\mathrm{A}^{\prime \prime}=\mathrm{A}+\mathrm{A}^{\prime}+(\mathrm{L}-\mathrm{N}) \mathrm{C}^{\prime}+\left(\mathrm{L}-\mathrm{N}^{\prime}\right) \mathrm{C}^{\prime \prime}$

$\mathrm{A}^{\prime \prime \prime}=\mathrm{A}-\mathrm{A}^{\prime}+\left(\mathrm{L}^{\prime}-\mathrm{N}\right) \mathrm{C}^{\prime}+\left(\mathrm{N}^{\prime}-\mathrm{L}^{\prime}\right) \mathrm{C}^{\prime \prime}$

Thus $\left(L-L^{\prime}\right)^{2}=\left(L+L^{\prime}-2 N\right)\left(L+L^{\prime}-2 N^{\prime}\right)$ and $(L-N)\left(N^{\prime}-L\right)=\left(L^{\prime}-N\right)\left(L^{\prime}-N^{\prime}\right)$ and $(L-N)\left(L^{\prime}-L\right)=(N$

'- $L)\left(L^{\prime}+L-2 N\right)$ and $-\left(L+L^{\prime}-2 N^{\prime}\right)\left(L^{\prime}-N\right)=-\left(L^{\prime}-L\right)\left(L^{\prime}-N^{\prime}\right)$ by the same calculus than higher

$\mathrm{N}=\mathrm{N}^{\prime}=\mathrm{L}=\mathrm{L}^{\prime}$ is unique !

Thus, there are finaly two possibilities

I) There are three subpossibilities : $C C^{\prime \prime}\left(C^{\prime \prime} C^{\prime \prime}\right)^{n}$ is transcendental for all $\mathrm{n}$, for all $\mathrm{T}$, $\mathrm{T}$ ' prime transcendental numbers, there exist $C=T C^{\prime \prime 1}, C^{\prime \prime}=T^{\prime} C^{\prime \prime \prime-1} \Rightarrow T T^{\prime n}$ is transcendental for all $\mathrm{n}$, particularly $\mathrm{n}=1$ and $\mathrm{TT}$ ' and $\mathrm{T}+\mathrm{T}^{\prime}$ are transcendentals. Or $C C^{{ }^{1-1}}\left(C^{\prime} C{ }^{\prime \prime}-{ }^{1}\right)^{n}$ is transcendental for all n, for all T, T' prime transcendental numbers, there exist $C=T C^{\prime-1}, C^{n^{-1}}=T^{\prime \prime-1} \rightarrow T T^{\prime n}$ is transcendental for all $\mathrm{n}$, particularly $\mathrm{n}=1$ and $\mathrm{TT} 4$ and $\mathrm{T}+\mathrm{T}$ ' are transcendent $\mathrm{s}$.

Third subpossibility : $C C^{\prime n}$ for all $n \neq M$ for all T, T' prime transcendental numb there exis 11 $C=T^{1 / 2}, C^{\prime}=T^{\prime 1 / n} \Rightarrow T T^{\prime}$ transcendental and $\mathrm{T}+\mathrm{T}^{\prime}$ transcendental.

II) There are three subpossibilities $C+C^{\prime \prime+m}\left(C^{\prime}+C^{\prime \prime \prime}\right)$ is transcendental for all $n$, for al $T^{\prime}$ prime transcendental numbers, there exist $\mathrm{C}=\mathrm{T}-\mathrm{C}^{\prime}, \mathrm{C}^{\prime}=\mathrm{T}^{\prime}-\mathrm{C}^{\prime \prime}$, and $\mathrm{T}+\mathrm{p}$ is tro iner ter al for all $\mathrm{m}$, particularly $\mathrm{m}=1$ and $\mathrm{T}+\mathrm{T}$ ' and $\mathrm{TT}$ ' are transcendent $\mathrm{O}$ ' $\mathrm{C}$ ' $+\mathrm{p}, \mathrm{C}-\mathrm{C}$ '" $)$ is transcendental for all $\mathrm{m}$, for all $\mathrm{T}, \mathrm{T}$ ' prime transcendenta vumbers, ve xist $\mathrm{C}=\mathrm{T}+\mathrm{C}$ ', $\mathrm{C}^{\prime}=\mathrm{T}^{\prime}+\mathrm{C}^{\prime \prime}$, and $\mathrm{T}+\mathrm{mT} \mathrm{T}^{\prime}$ is transcendental for all $\mathrm{m}$, parti ala $\mathrm{m}=1$ and $4 \mathrm{~T}^{\prime}$ and $\mathrm{TT}^{\prime}$ are transcendentals. Third subpossibility : $\mathrm{C}+\mathrm{mC}^{\prime}$ is tran shental all $m \neq N$. For all $\mathrm{T}, \mathrm{T}$ ' prime transcendental numbers, there exist $2 \mathrm{C}=1, \mathrm{mC}^{\prime}=\mathrm{T}^{\prime} \mathrm{a}_{\mathrm{a}} / \mathrm{T}+\mathrm{T}^{\prime}$ and $\mathrm{TT} 4$ are
transcendentals.

The theorem application

$T=\pi, T^{\prime}=e$ implie that the sum and the produt and e armuscendentals.

\section{The approach of Riemann hypothesis}

The Rieman hypothesis states that eros of the Riemann zeta function $\zeta(z)=\sum_{t=1}^{\infty} \frac{1}{t^{z}}$

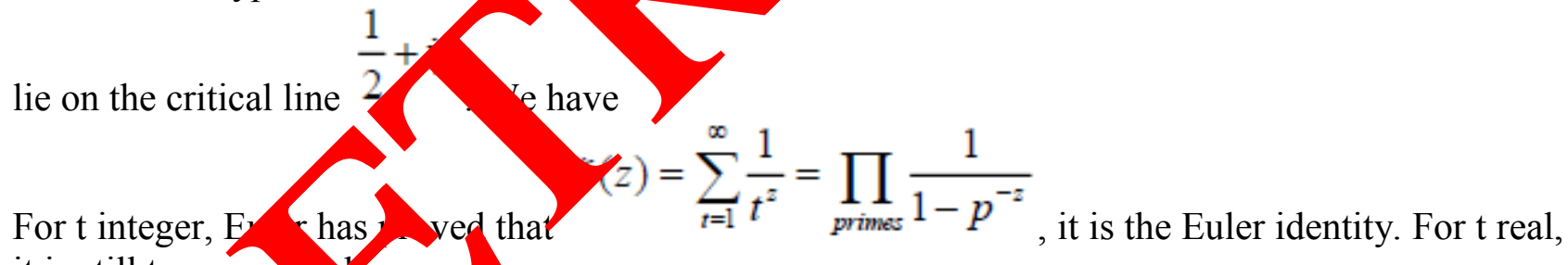
it is still tru $=$ e an

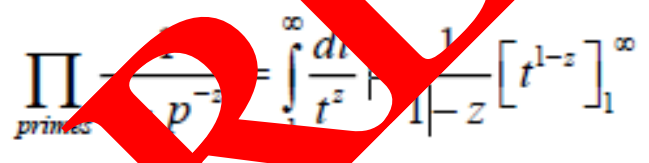

But there are the tivial zeros : we have $\zeta(-2 k)=-k \in N$ and $\left[t^{1+2 k}\right]_{1}^{\infty}=0$ but if $\left[t^{z}\right]^{\infty}$ but if $\left[t^{z}\right]^{\infty}$ is the limit in the infinity, $\left[t^{1+2 k}\right]^{\infty}=1, \forall k \in N$ and

$\left.\left[t^{1-\frac{1}{2}-i y}\right]^{\infty}=\left[t^{\frac{1}{2}-i y}\right]^{\infty}=\left[t^{\frac{1}{2}+\dot{y} y}\right]^{\infty}=\frac{1}{2}\left(t^{\frac{1}{2}-i y}\right]^{\infty}+\left[t^{\frac{1}{2}+i y}\right]^{\infty}\right)=a$

$\Rightarrow\left[t^{2\left(\frac{1}{2}+\dot{y} y\right)}-2 a t^{\frac{1}{2}+\dot{x} y}+t\right]^{\infty}=\left[t^{2\left(\frac{1}{2}+\dot{y} y\right)}-2 a t^{\frac{1}{2}+\dot{y} y}+1\right]^{\infty}=0 \Rightarrow\left[t^{\frac{1}{2}+\dot{y} y}\right]^{\infty}=a=a+\sqrt{a^{2}-1}=1$ 
it means that

$$
\zeta\left(\frac{1}{2}+i y\right)=\left[\frac{1}{1-\frac{1}{2}-i y} t^{1-\frac{1}{2}-i y}\right]_{1}^{\infty}=0
$$

Let now

$$
\zeta(x+i y)=0=\left[\frac{t^{1-x-i y}}{1-x-i y}\right]_{1}^{\infty}=\left[\frac{t^{\frac{1}{2}-i y} t^{\frac{1}{2}-x}}{1-x-i y}\right]_{1}^{\infty}=\left[\frac{t^{\frac{1}{2}-x}}{1-x-i y}\right]_{1}^{\infty}=0 \Rightarrow x=\frac{1}{2}
$$

We have proved that the non trivial zeros of the Riemann function for the reals lie in 1 le crme ! So the hypothesis for the real numbers is proved. The Riemann hypothesis is in rrtant beca e it gives information about the zeros of the Riemann function and the distributinn on ore zero are related to real primes!

\section{Conclusion}

Through this exposé, we have given a method to find the nature geral num we have shown the nature of some of them. We have also generalized the Rie ann othesis $y$ the real numbers and proved it !

\section{References}

[1] Alan Baker, Transcendental number theory, Cam dge uni ersity press, 1975

[2] Karl Sabbagh, The Riemann hypothe the grean ansolved problem in mathematics, Farrar, Straus and Giroux, 2004.

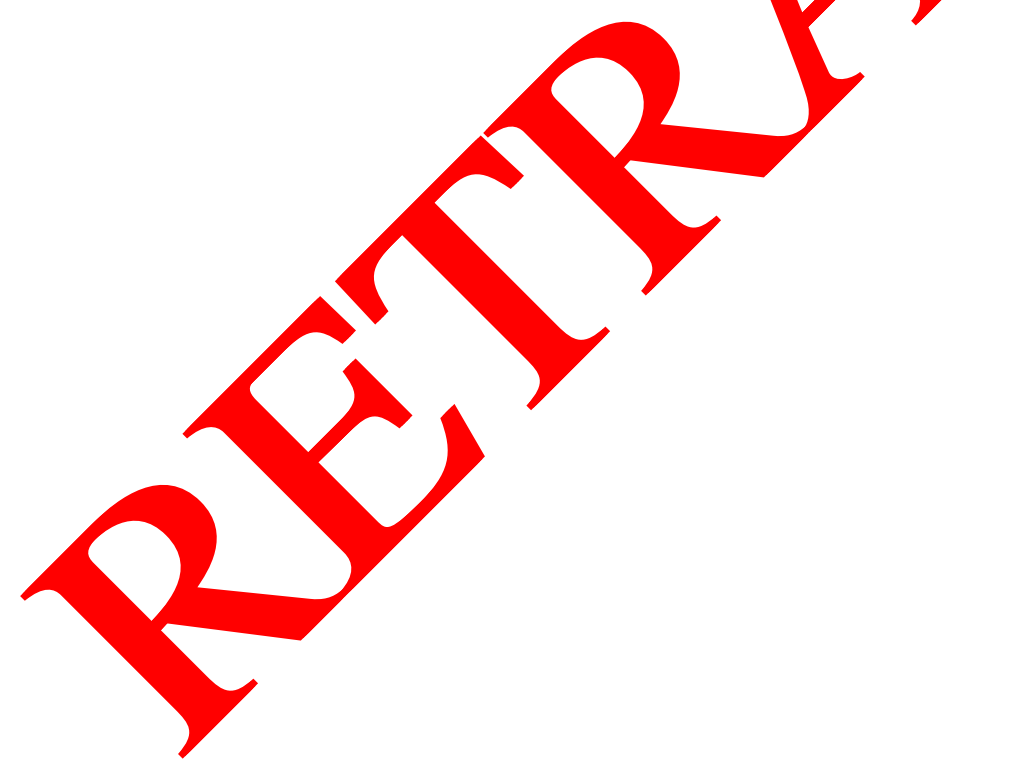

